\title{
From bad to worse? Effects of multiple adverse life course transitions on mental health
}

\author{
Jornt J. Mandemakers \\ j.j.mandemakers@uu.nl \\ Matthijs Kalmijn
}

(Received November 2017
Utrecht University, the Netherlands

University of Amsterdam, the Netherlands

Revised May 2018)
http://dx.doi.org/10.14301/Ilcs.v9i3.484

\section{Abstract}

This paper examines whether the simultaneous occurrence of two or more adverse life course transitions has a stronger effect on mental health compared to the effects of the sum of each. The focus is on four life course transitions (partner loss (divorce/separation or death), death of a parent, unemployment, disability) and the data come from a large four-wave longitudinal dataset in the Netherlands ( $N=4,192$ respondents). There is clear evidence that negative life course transitions tend to cluster. Of the four transitions, partner loss and disability onset have the largest negative impact on mental health but unemployment also has a clear effect. There is not only additive but also interactive accumulation during the life course: one adverse event has a more negative impact on mental health when it occurs simultaneously with another. This provides evidence on the link between 'turbulent times' in the life course and negative mental health trajectories. We did not find evidence that effects of adverse transitions depend on education.

\section{Keywords}

Life course transition; mental health; mhi-5; partner separation; unemployment; disability; parental death; accumulation; the Netherlands

\section{Introduction}

There is ample research into the effect of life course transitions on wellbeing and mental health. Research on the domains of work, health, and family indicate that several life course transitions can reduce mental health. Partner loss, in the family domain, is well known to impair people's mental health (Amato, 2000; Amato \& Cheadle, 2005). The loss of close family members, such as the death of a parent, may also hurt wellbeing and mental health (Ballas \& Dorling, 2007; Marks, Jun \& Song, 2007; Umberson, 1995). In the work domain, the loss of a job and the experience of unemployment are important transitions that affect mental health (Dooley, Fielding \& Levi, 1996; Kasl \& Jones, 2000; Korpi, 2001; Paul \& Moser, 2009). Furthermore, physical health is important for people's wellbeing; declines in physical health are associated with marked declines in wellbeing (Kelley-Moore \& Ferraro, 2005; Lucas, 2007; Oswald \& Powdthavee, 2008; Turner \& Noh, 1988).

The main approach taken by research on mental health is to consider life course transitions one at a time. Studies typically focus on one domain and one transition in one paper or one model. Life courses in different domains are interconnected, however. A change in one domain of life may lead to or coincide with a change in another domain. For example, the relationship history and employment career are strongly intertwined; a common finding is that union dissolution heightens the risk of unemployment (Charles \& Stephens, 2004; Covizzi, 2008; Kalmijn, 2005) and vice versa (Hansen, 2005). 
Furthermore, parental death is related to marital problems (Umberson, 1995) and because marital problems increase the risk of divorce (Amato \& Rogers, 1997), parental death may be associated with partner loss. Interconnectedness also exists in other domains. For example health transitions and transitions into and out of unemployment are clearly associated (García Gómez \& López Nicolás, 2006; Van de Mheen, Stronks, Schrijvers \& Mackenbach, 1999; Schuring, Burdoff, Kunst \& Mackenbach, 2007; Wagenaar et al., 2012) but disability and divorce are associated as well (Kalmijn, 2005; Wilson \& Waddoups, 2002). The interconnectedness of the various life domains and the synchronicity of transitions imply that some people will experience multiple adverse transitions in a short period of time (e.g., partner loss and unemployment). Such 'turbulent' periods may have especially profound negative consequences for mental health. Although studies of particular life course transitions sometimes include information on 'other' domains of life, this information is mostly used as a control variable.

A second approach to mental health, which is more often applied in public health research and some psychological studies, is to consider a range of 'events' simultaneously by constructing cumulative measures of life events, typically retrospectively assessed (Kessler, 1997; Lantz, House, Mero \& Williams, 2005; Turner, Wheaton \& Lloyd, 1995). Research along such lines shows that people who experience several negative life events have lower mental health and a heightened risk of depression (Turner \& Avison, 1992; Turner et al., 1995). These findings suggest that 'turbulent' periods may be especially harmful to wellbeing and mental health: the more adverse life course transitions people experienced, the lower their wellbeing. The 'life event' approach has the merit that life course transitions are no longer viewed in isolation. A disadvantage, however, is that rather different events such as loss of a partner and parental death, are treated as equivalent: the scales for life events are simple counts of the number of events that occurred. Another limitation is that lifetime events are sometimes mixed with more recent events to create measures of total lifetime stress (e.g., Reynolds \& Turner, 2008), which complicates the interpretation of the findings. Finally, in the life events approach a number of strains and events (e.g. financial problems, partner infidelity) that are associated with adverse life course transitions (e.g., job loss and partner loss) are treated as life events as well (see for example Turner et al., 1995). This practice may inflate the number of life events in the scale.

In studying how multiple life course transitions affect mental health, there are two theoretical approaches possible. One hypothesis is that the occurrence of multiple adverse transitions leads to worse outcomes than what each transition on its own would imply. This reasoning is based on an interactive influence of the various transitions: the experience of one adverse event becomes more painful when another transition occurs at the same time. The basis for this idea lies in the notion of resources. Adverse life course transitions tend to decrease people's social and economic resources. For example, following the death of a parent it may be harder to deal with partner loss as one can no longer turn to a parent for help and the loss of a parent may be harder to face without a partner. Similarly, it may be more difficult to deal with unemployment in combination with separation as there is no longer a partner at home who can provide emotional support, and former colleagues may be less likely to be a source of support in dealing with the separation. Similar negative patterns are imaginable for the other combinations of life course transitions, such as disability and partner loss or disability and job loss. A related idea is that a reduction in mental health makes people more vulnerable in an emotional sense because it reduces the psychological (coping) resources that people normally have (Thoits, 1982). Because adverse life course transitions reduce people's resources, the experience of another adverse life course transition will be particularly problematic and reduce mental health more than one would expect if that transition had occurred on its own.

An alternative hypothesis is based on an additive influence of the various transitions: each transition reduces mental health and if people experience multiple transitions, the total decline in mental health is the sum of the individual effects. Two main reasons can be given for such a simple additive pattern of effects: support mobilisation and floor effects. First, people who experience multiple life course transitions in a short span of time may be more likely to ask and receive support compared to people who experience just one transition. When people receive more support, this may 
counterbalance the negative interactive effects of experiencing several adverse transitions. If support is mobilised, it is often given for more than one problem at a time, which may reduce the interactive effects of multiple transitions. Second, there may be a floor effect operating. A first transition affects mental health in a negative way. For the next transition, when life is already in turmoil, another change may still have damaging potential but it will not have an extra negative effect and could even have a weaker effect if the initial effect is already severe. This possible floor effect may counterbalance the interactive effects of psychological vulnerability and decreased resources.

Which scenario is true - interactive or additive has important implications for how inequality accumulates across the life course. If the additive scenario is valid, people who experience one event are more likely to experience another event and this leads to increasing inequality in mental health across the life course. This is important for inequality but only to the extent that adverse transitions tend to cluster in persons. If the interactive scenario is valid, inequality during the life course is increased for two reasons: adverse transitions cluster and they have interactive effects on life chances. Clearly, the latter scenario implies a more serious accumulation of inequality during the life course than the former. So far, the literature has been unclear about the nature of accumulation and the typical analysis has not clearly tested interaction effects vis-à-vis additive effects of life course transitions.

Another approach to accumulation has been to examine to what extent the effects of certain life course transitions depend on socioeconomic conditions; the differential vulnerability perspective (McLeod \& Kessler, 1990). Examples of this perspective are studies on how the effects of divorce on children's mental health depend on parental education (Bernardi \& Radl, 2014; Mandemakers \& Kalmijn, 2014) and studies of how employment effects on health differ depending on a person's prior occupational position (Mandemakers \& Monden, 2013). A common hypothesis is that lower strata - due to more limited economic, cultural, and psychological resources - are more vulnerable for the impact of adverse events. For partner loss, disability, and (to a lesser extent) unemployment, such effects have been demonstrated, especially for education (Clark, Georgellis \& Sanfey, 2001 in Germany; Mandemakers \& Monden, 2010, 2013, Mandemakers, Monden \& Kalmijn, 2010 in the UK; and Strully, 2009 in the USA). Whether such interactions also apply to the effects of multiple life course transitions, i.e., to simultaneous adverse events, is not known.

In this paper, we study accumulation by examining the impact of multiple adverse life course transitions on mental health. We improve on the "one transition at a time" and the "life events" literatures by focusing on four major life course transitions simultaneously. We examine partner loss (divorce/separation or death of a partner), the death of a parent, unemployment, and the experience of a serious deterioration in health (called 'disability' in this paper). These are not only adverse life events but they also change the roles that people occupy (e.g. from worker to nonworker, from healthy person to sick person) and are therefore considered life course transitions as well (Wheaton, 1990). We use large-scale longitudinal data from the Netherlands to examine life course effects and we systematically compare additive and interactive dynamic models to examine their combined impact. We also examine if effects of (combined) transitions depend on a person's level of education.

\section{Data, measurement, and design Data}

This study uses data from four waves of the Netherlands Kinship Panel Study (the waves were carried out in 2002-2004, 2006-2007, 2010-2011, and 2014-2015, the mean interval between waves was 3.5 years). Respondents were drawn from a random sample of private addresses in the Netherlands $(N=8,161)$. The overall response rate of the primary respondents was $45 \%$, which is comparable to other family surveys in the Netherlands (Dykstra et al., 2005). Response rates of follow-up waves were $74 \%$ for the second, $72 \%$ for the third, and $65 \%$ for the fourth wave (de Hoon, Dykstra, Komter, Liefbroer \& Mulder, 2015). We limited the analyses to respondents who were observed for at least two subsequent waves and to waves of respondents when they were at most 60 because unemployment may be different for people approaching retirement age and pensioners cannot become unemployed. In addition, as people age, health declines and the death of a parent may be 
the expected course of transitions. This does not mean that such transitions are no longer problematic but they will have a rather different nature earlier in the life course. This left us with 4,543 respondents and 13,791 respondent-wave combinations. We used listwise deletion of missing values. The final analytic sample encompasses 4,192 respondents who were observed for at least two subsequent waves and 12,770 respondentwave combinations. At baseline, the people that were not included were more likely to be men, had a slightly lower educational level and were somewhat more likely to have a physical disability, not to have a job and to be single. There were no differences with regard to baseline mental health, whether parents were alive, and the number of children.

\section{Measurement}

We measured mental health with the five-item mental health screening test MHI-5 (Berwick et al., 1991). This test consists of five questions about how the respondent felt in the past four weeks: (a) how often the respondent was tense, (b) how often the respondent was feeling so down that nothing could cheer him/her up, (c) how often the respondent was calm and peaceful, (d) how often the respondent felt miserable and depressed, (e) how often the respondent felt happy. Answers range from 1 "all the time" to 6 "never". The two positively worded items (c and e) were reversed. The scale is the average of the items and the resulting scale was standardised (mean $=0$, s.d. $=$ 1 ), which facilitates interpretation of the estimated coefficients in the linear regression as effect sizes. The reliability of this scale is good (alpha is .85). The correlation between waves is about .55. Cuijpers, Smits, Donker, ten Have, and de Graaf (2009) show that the MHI-5 is a good predictor of mood disorders (major depression, dysthymia), but less so of anxiety disorders. As such, the MHI-5 is often used as a measure of depressed mood and psychological mental health (e.g. Giver, Faber, Hannerz, Strøyer \& Rugulies, 2010).

Respondents were categorised in distinct life course trajectories for each domain, based on their status at each wave. We focus on the changes in status between waves ( $t$ to $t+1$ ). The analyses focus on the four transitions of interest (partner loss, death of a parent, unemployment and disability onset) and include other transitions in relevant domains (e.g. partnership formation in the partnership domain) and age as control variables.

Respondents were asked for their relationship status at each wave. We consider partnership as either cohabitation or marriage. We distinguish the following three relationship transitions between two subsequent waves ( $t$ to $t+1$ ): (1) from being single to having a partner; (2) from having a partner to being single; (3) from having a partner to having a different partner (re-partnered). Partner loss (category 2 and 3 ) consists of people who divorce or separate and includes people whose partner died. Death of a partner is uncommon (21 out of 342 partner losses). The reference group consists of people who remained with the same partner and those who remained single from one wave to the next.

We considered whether a parental death (mother or father or both) occurred in between subsequent waves ( $t$ to $t+1)$. No parental death observed between waves is the reference.

The main current economic activity was used to classify respondents into three groups: employed (includes pregnancy leave), unemployed (unemployed and those on a disability benefit), and inactive (ranging from homemakers, students to pensioners). Receiving disability benefits was included in the unemployment category; disability itself was treated as a separate transition (for further discussion, see below). It has been suggested that a substantial part of enrolment into disability benefits in the Netherlands is hidden unemployment (Koning \& van Vuuren, 2010). We distinguish the following four employment transitions between waves ( $t$ to $t+1)$ : (1) employment/inactive to unemployment; (2) unemployment to employment/inactive; (3) employment to inactive; (4) inactive to employment. The reference is if there was no change between waves (remained employed, unemployed or inactive).

Two questions in each wave were posed regarding disability. Note that the term disability is not used here in the sense of disability from work, but in the sense of having a long-standing illness or a disability that limits people in their daily life. Hence, people do not necessarily have to stop working if they have a disability. We first asked respondents if they had such an illness or disability and if so, to what extent it limited them in their life. Based on these questions we examined the 
following two transitions between waves ( $t$ to $t+1$ ): (1) no disability or a disability with light limitations to a disability with severe limitations; (2) disability with severe limitations to no disability or to a disability with light limitations. The reference is if there was no change between waves (remain without disability/light limitations, remain with severe limitations).

Education was categorised in 11 levels that were recoded into three distinct educational groups: primary/lower secondary level (only primary education or lower and lower secondary level); higher secondary level/vocational; tertiary and higher). These three levels reflect the main social divide by educational level in the Netherlands. This coding was done to make our tests more parsimonious and was based on previous work in the field of social mobility research (De Graaf \& Ganzeboom, 1993). We used the reported level of education in the first of each set of subsequent pairs of waves, so it can vary within individuals over the course of the study. Table 1 reports the descriptive statistics for the dependent and independent variables.

Table 1. Descriptive statistics $(N=8,578)$

\begin{tabular}{lll}
\hline & mean & sd \\
\hline change score MHI-5 (std.) & .02 & .97 \\
change score age (std.) & 3.60 & .53 \\
educational level & \\
$\quad$ primary/lower secondary (ref.) & .21 \\
$\quad$ secondary/vocational & .36 \\
$\quad$ tertiary & .43 \\
parenthood transitions & \\
$\quad$ no new child (ref.) & .87 \\
got new child & .13 \\
$\quad$ no change in parenthood status (ref.) & .94 \\
became parent first time & .06 \\
partnership transitions & \\
$\quad$ no change in partnership (ref.) & .90 \\
entered partnership & .06 \\
$\quad$ became single & .03 \\
$\quad$ repartnered with new partner & .01 \\
parental transitions & \\
$\quad$ no change in parental vital status (ref.) & .88 \\
$\quad$ one or both parents died & .12 \\
employment transitions & \\
$\quad$ no change in employment status (ref.) & .83 \\
entered unemployment & .04 \\
left unemployment & .03 \\
employment -> inactive & .04 \\
inactive -> employment & .06 \\
health transitions & \\
$\quad$ no change in health (ref.) & .94 \\
became disabled & .03 \\
regained health & .03 \\
simultaneous transitions & .02 \\
\hline
\end{tabular}




\section{Design}

In our first set of models, we estimate the effect of simultaneous adverse transitions on mental health (table 3). We model the level of mental health using first difference regression (change score models). First differences regression predicts changes in mental health by transitions between two subsequent waves. All time constant (un)observed individual differences are thereby differenced out, such as pre-existing differences in mental health and other relevant confounders. This is akin to fixed effect regression except that we here only contrast a current wave with a previous wave (hence first difference). Fixed-effect regression cannot be used for our purposes because we want to differentiate positive (e.g. becoming married) from adverse transitions (e.g. partner loss). Fixed-effect models equate positive and negative changes, which make sense for studying a change in a continuous variable such as income (increase/decrease), but not necessarily for events/transitions in the life course such as in relationship status (marriage versus divorce). Similar to fixed-effects regression the estimates of our models rely on withinindividual variation.

Note that respondents participated for at least two and at most four waves $(N=12,770$ respondent-wave combinations, which covered 7.4 years of a respondent's life on average), so we observed between one and three pairs of subsequent waves per individual. The observations in our analysis consist of the pooled 8,578 instances of subsequent pairs of waves for
4,192 respondents. Standard errors were adjusted for clustering of multiple observations in individuals in all models.

We included the main effects of the transitions between waves and added an additional variable indicating whether or not a respondent experienced more than one transition into a negative state. The 'simultaneous event' variable is central to our paper: it estimates to what extent there is an extra effect on mental health on top of the effects of each separate transition. 174 respondents experienced more than one adverse event between two sequential waves, of which three experienced it twice. So, we observed 177 simultaneous adverse transitions in total. This is sufficient to estimate the effect of simultaneous transitions. We estimate that we would need at least 130 observations in the 'experimental group' of simultaneous transitions to detect an effect size of $d=.25$ at alpha $5 \%$. Unfortunately, there were not enough transitions for each specific event combination (e.g. for simultaneous unemployment entry and partner loss $N=20$ ) to allow further delineation into specific combinations of transitions (see table 2 for the number of transitions per combination).

In our last set of analyses (table 4), we examined whether education moderates the impact of the (combined) transitions we study. Specifically, we repeat the primary analysis (table 3 ) for each of three educational groups. We thus present three sets of two models: the base model and the model including the simultaneous transitions indicator.

Table 2. Simultaneous transition breakdown $(N=8,578)$

\begin{tabular}{lccc}
\hline $\begin{array}{l}\text { Combinations of simultaneous } \\
\text { transitions }\end{array}$ & $N^{a}$ & Odds ratio & $\begin{array}{c}\text { Adjusted } \\
\text { odds ratio }^{b}\end{array}$ \\
\hline Any simultaneous transition & 177 & - & - \\
Partner loss * Unemployment & 20 & $1.68^{*}$ & $1.72^{*}$ \\
Partner loss * Disability & 11 & 1.01 & .91 \\
Partner loss * Death of a parent & 35 & .83 & .88 \\
Unemployment * Disability & 46 & $5.94^{* * *}$ & $5.88^{* * *}$ \\
Unemployment * Death of a parent & 39 & 1.02 & .86 \\
Disability * Death of a parent & 50 & $1.63^{* *}$ & $1.51^{* *}$ \\
\hline
\end{tabular}

\footnotetext{
${ }^{\text {a }} N$ of transition combinations does not add up to 177 because some respondents experience more than two transitions simultaneously; ${ }^{b}$ adjusted for wave, age, sex and the other transitions;

* $p<0.05 ;{ }^{* *} p<0.01 ;{ }^{* * *} p<0.001$, two-tailed
} 


\section{Results}

\section{Occurrence of adverse transitions}

We observed a total of 177 simultaneous transitions, which is only $0.2 \%$ of the 8,578 observations. This shows that it is uncommon to experience multiple adverse transitions and that one needs very large samples to study these issues. Table 2 shows the odds ratios of experiencing the six possible simultaneous combinations of the four delineated adverse transitions. Several combinations of transitions had odds ratios that differed significantly from 1 . People who become unemployed are more likely to lose a partner ( $72 \%$ more likely after adjusting for covariates) and, conversely, partner loss increases the odds of unemployment. It is clear that becoming unemployed and becoming disabled are associated; one is almost six times more likely to observe the onset of disability if someone becomes unemployed and vice versa. Also parental death and the onset of a disability seem to be related, as the odds ratio is about 1.6.

\section{First difference regression}

We now turn to the question of accumulation of adverse transitions on mental health. Table 3 shows the results of two first difference regression models. Model 1 is the base model of mental health regressed on transitions in the life course domains and a set of control transitions. As we use first difference models the results refer to changes in levels of mental health within individuals following changes in their lives (akin to fixed-effects regression). The reference group consists of the observations where we did not observe an event in between the waves. The coefficients of the dummy variables can be interpreted as effect sizes because the dependent variable is standardised. We first turn to the controls and then to the transitions.

Table 3. First difference regression of MHI-5.

\begin{tabular}{|c|c|c|c|c|}
\hline & \multicolumn{2}{|c|}{$\begin{array}{l}\text { (1) } \\
\text { base }\end{array}$} & \multicolumn{2}{|c|}{$\begin{array}{c}(2) \\
\text { simultaneous transitions }\end{array}$} \\
\hline & b & se & b & se \\
\hline change score age (std.) & -.024 & $(.020)$ & -.024 & $(.020)$ \\
\hline \multicolumn{5}{|l|}{ parenthood transitions } \\
\hline got new child & $-.081^{*}$ & $(.040)$ & $-.080^{*}$ & $(.040)$ \\
\hline became parent first time & .009 & $(.058)$ & .009 & $(.057)$ \\
\hline \multicolumn{5}{|l|}{ partnership transitions } \\
\hline entered partnership & $.129^{* *}$ & $(.045)$ & $.130^{* *}$ & $(.045)$ \\
\hline became single & $-.226^{* * *}$ & $(.058)$ & $-.182^{* *}$ & $(.060)$ \\
\hline $\begin{array}{l}\text { repartnered with new } \\
\text { partner }\end{array}$ & .236 & $(.130)$ & $.266^{*}$ & $(.130)$ \\
\hline \multicolumn{5}{|l|}{ parental transitions } \\
\hline & \multicolumn{2}{|c|}{ employment transitions } & & $(.033)$ \\
\hline entered unemployment & $-.191^{* * *}$ & $(.056)$ & $-.130^{*}$ & $(.060)$ \\
\hline left unemployment & $.146^{*}$ & $(.065)$ & $.145^{*}$ & $(.065)$ \\
\hline employment -> inactive & .102 & $(.055)$ & .102 & $(.055)$ \\
\hline inactive -> employment & .024 & $(.046)$ & .025 & $(.046)$ \\
\hline \multicolumn{5}{|l|}{ health transitions } \\
\hline became disabled & $-.348^{* * *}$ & $(.060)$ & $-.272^{* * *}$ & $(.066)$ \\
\hline regained health & $.273^{* * *}$ & $(.060)$ & $.273^{* * *}$ & $(.060)$ \\
\hline simultaneous transitions & & & $-.253^{* *}$ & $(.093)$ \\
\hline constant & .126 & $(.073)$ & .121 & $(.072)$ \\
\hline$N$ observations & \multicolumn{2}{|c|}{8578} & \multicolumn{2}{|c|}{8578} \\
\hline$N$ individuals & \multicolumn{2}{|c|}{4192} & \multicolumn{2}{|c|}{4192} \\
\hline
\end{tabular}


${ }^{*} p<0.05 ;{ }^{* *} p<0.01 ; * * * p<0.001$, two-tailed

Mental health does not change as people age, but note that the sample is limited to people below 60. Becoming a parent for the first time was not associated with a change in mental health, but the number of children was negatively associated with mental health.

Changes in the main life course domains will be discussed below. In the family domain, we find that people who experience partner loss (either through divorce/separation or death) experience a decrease in mental health. Becoming single has an effect size of -.226 , which is modest. Re-partnering mitigates the negative effect of partner loss, as people who lost a partner between waves and who re-partner do not experience a decrease in mental health. The predicted change is even positive, although not significantly different from zero. People who enter a partnership experience a significant but small increase in mental health (.129). People who experience the loss of a parent (one or both) do not suffer the expected decrease in mental health. The effect $(-.050)$ is in the expected direction but too small to be significantly different from zero. Transitions in the employment career also affect mental health. Those who become unemployed between waves have, as expected, a significantly lower level of mental health (-.191). Transitions out of unemployment lead to an increase in mental health but transitions in and out of the labour market do not affect it. Disabilities are quite important for mental health, as the following findings show. People who experience the onset of a disability have a decrease in mental health (-.348). People who were no longer limited by a disability experience an increase in mental health (.273). Note that models differentiating in the level of change in health over time show that the health shock is contingent on the level of disablement (not shown, available upon request).

Model 1 implies people who experience several adverse transitions accumulate adversity that reduces their mental health. It does not answer our main question of whether accumulation is additive or interactive. To answer that question, model 2 adds an indicator that measures whether people had experienced two or more adverse transitions between subsequent waves ('simultaneous transitions'). This effect tests our hypothesis of interactive effects. There appear to be amplifying interactive effects as the effect of this indicator is significant and negative (-.253). The main effects of the adverse transitions remain significant once we allow for interactive effects, although the size of these effects is reduced. This is especially the case for unemployment $(-.191$ to -.130 , a reduction by almost a third), which suggests that part of the unemployment effect is related to experiencing simultaneous adversity in other domains of life. Only the positive effect of repartnering slightly increases between models 1 and 2 and is now significantly different from zero (increased from .236 to .266). Note that the reduction in the main effects of these adverse transitions (model 2 versus 1) cannot make up for the additional decrease in mental health due to experiencing simultaneous adverse transitions (-.253 versus a decrease from .191 to -.130 for the unemployment effect), so these findings provide support for the idea that adversity accumulates. Further note that sample size restrictions did not permit us to investigate which combinations of transitions were most detrimental to mental health.

Finally, we evaluate the possibility that having a higher education benefits people by making the impact of adverse transitions weaker. We tested for moderation by stratifying the main analysis into three educational groups and tested whether the coefficients were statistically equivalent or not (table 4, model 1). Education did not moderate the impact of adverse transitions in the Netherlands. No significant interactions effects were found for partner loss, parental death, unemployment, and for disability. Only one effect was significantly different; the lowest educated seem to benefit from repartnering following partner loss as their mental health is predicted to increase by about 1 standard deviation. However, there were only 11 people in the lowest educational group who experienced this so we do not attach too much value to this finding. We note that there is some evidence that becoming single has a stronger negative effect for people with less education, whereas unemployment and disability have a more negative impact for the higher educated. These differences are tentative since they are not statistically significant. 
Table 4. First difference regression of MHI-5 by education.

\begin{tabular}{|c|c|c|c|c|c|c|}
\hline & \multicolumn{3}{|c|}{ base } & \multicolumn{3}{|c|}{ simultaneous events } \\
\hline & $\begin{array}{c}\text { primary/ } \\
\text { lower } \\
\text { secondary } \\
\text { b/se }\end{array}$ & $\begin{array}{c}\text { secondary/ } \\
\text { vocational } \\
\text { b/se }\end{array}$ & $\begin{array}{c}\text { tertiary } \\
\text { b/se }\end{array}$ & $\begin{array}{c}\text { primary/ } \\
\text { lower } \\
\text { secondary } \\
\text { b/se }\end{array}$ & $\begin{array}{c}\text { secondary/ } \\
\text { vocational } \\
\text { b/se }\end{array}$ & tertiary \\
\hline change score age (std.) & $\begin{array}{l}.004 \\
(.048)\end{array}$ & $\begin{array}{l}-.036 \\
(.034)\end{array}$ & $\begin{array}{l}-.020 \\
(.028)\end{array}$ & $\begin{array}{l}.004 \\
(.048)\end{array}$ & $\begin{array}{l}-.035 \\
(.034)\end{array}$ & $\begin{array}{l}-.020 \\
(.028)\end{array}$ \\
\hline parenthood transitions & & & & & & \\
\hline got new child & $\begin{array}{l}-.083 \\
(.116)\end{array}$ & $\begin{array}{l}-.094 \\
(.069)\end{array}$ & $\begin{array}{l}-.068 \\
(.052)\end{array}$ & $\begin{array}{l}-.084 \\
(.116)\end{array}$ & $\begin{array}{l}-.096 \\
(.069)\end{array}$ & $\begin{array}{l}-.067 \\
(.052)\end{array}$ \\
\hline became parent first time & $\begin{array}{l}-.014 \\
(.199)\end{array}$ & $\begin{array}{l}.021 \\
(.100)\end{array}$ & $\begin{array}{l}.017 \\
(.071)\end{array}$ & $\begin{array}{l}-.015 \\
(.199)\end{array}$ & $\begin{array}{l}.022 \\
(.099)\end{array}$ & $\begin{array}{l}.017 \\
(.071)\end{array}$ \\
\hline partnership transitions & & & & & & \\
\hline entered partnership & $\begin{array}{l}.374^{* *} \\
(.133)\end{array}$ & $\begin{array}{l}.115 \\
(.075)\end{array}$ & $\begin{array}{l}.080 \\
(.060)\end{array}$ & $\begin{array}{l}.375^{* *} \\
(.133)\end{array}$ & $\begin{array}{l}.121 \\
(.075)\end{array}$ & $\begin{array}{l}.080 \\
(.060)\end{array}$ \\
\hline became single & $\begin{array}{l}-.262 \\
(.135)\end{array}$ & $\begin{array}{l}-.236^{*} \\
(.095)\end{array}$ & $\begin{array}{l}-.206^{*} \\
(.088)\end{array}$ & $\begin{array}{l}-.284 \\
(.145)\end{array}$ & $\begin{array}{l}-.112 \\
(.098)\end{array}$ & $\begin{array}{l}-.193^{*} \\
(.089)\end{array}$ \\
\hline $\begin{array}{l}\text { repartnered with new } \\
\text { partner }\end{array}$ & $\begin{array}{l}1.048^{* *} \\
(.366)\end{array}$ & $\begin{array}{l}.086 \\
(.203)\end{array}$ & $\begin{array}{c}.038 \\
(.184)\end{array}$ & $\begin{array}{l}1.032^{* *} \\
(.368)\end{array}$ & $\begin{array}{l}.193 \\
(.204)\end{array}$ & $\begin{array}{c}.045 \\
(.184)\end{array}$ \\
\hline parental transitions & & & & & & \\
\hline one or both parents died & $\begin{array}{l}-.082 \\
(.072)\end{array}$ & $\begin{array}{l}-.027 \\
(.056)\end{array}$ & $\begin{array}{l}-.055 \\
(.046)\end{array}$ & $\begin{array}{l}-.093 \\
(.076)\end{array}$ & $\begin{array}{c}.038 \\
(.057)\end{array}$ & $\begin{array}{l}-.046 \\
(.047)\end{array}$ \\
\hline employment transitions & & & & & & \\
\hline entered unemployment & $\begin{array}{l}-.184 \\
(.114)\end{array}$ & $\begin{array}{l}-.099 \\
(.093)\end{array}$ & $\begin{array}{l}-.317^{* * *} \\
(.091)\end{array}$ & $\begin{array}{l}-.205 \\
(.124)\end{array}$ & $\begin{array}{l}.078 \\
(.101)\end{array}$ & $\begin{array}{l}-.290^{* *} \\
(.096)\end{array}$ \\
\hline left unemployment & $\begin{array}{l}.348^{* *} \\
(.129)\end{array}$ & $\begin{array}{l}.012 \\
(.112)\end{array}$ & $\begin{array}{l}.050 \\
(.103)\end{array}$ & $\begin{array}{l}.349^{* *} \\
(.130)\end{array}$ & $\begin{array}{l}-.003 \\
(.112)\end{array}$ & $\begin{array}{l}.052 \\
(.103)\end{array}$ \\
\hline employment -> inactive & $\begin{array}{l}.102 \\
(.117)\end{array}$ & $\begin{array}{l}.062 \\
(.093)\end{array}$ & $\begin{array}{c}.142 \\
(.087)\end{array}$ & $\begin{array}{l}.102 \\
(.117)\end{array}$ & $\begin{array}{l}.064 \\
(.093)\end{array}$ & $\begin{array}{c}.142 \\
(.087)\end{array}$ \\
\hline inactive -> employment & $\begin{array}{l}.108 \\
(.107)\end{array}$ & $\begin{array}{l}-.011 \\
(.068)\end{array}$ & $\begin{array}{l}-.013 \\
(.078)\end{array}$ & $\begin{array}{l}.107 \\
(.107)\end{array}$ & $\begin{array}{l}-.010 \\
(.068)\end{array}$ & $\begin{array}{l}-.013 \\
(.078)\end{array}$ \\
\hline health transitions & & & & & & \\
\hline became disabled & $\begin{array}{l}-.160 \\
(.123)\end{array}$ & $\begin{array}{l}-.449^{* * *} \\
(.095)\end{array}$ & $\begin{array}{l}-.437^{* * *} \\
(.101)\end{array}$ & $\begin{array}{l}-.187 \\
(.138)\end{array}$ & $\begin{array}{l}-.271^{* *} \\
(.103)\end{array}$ & $\begin{array}{l}-.396^{* * *} \\
(.113)\end{array}$ \\
\hline regained health & $\begin{array}{l}.152 \\
(.111)\end{array}$ & $\begin{array}{l}.399^{* * *} \\
(.104)\end{array}$ & $\begin{array}{r}.250^{*} \\
(.104)\end{array}$ & $\begin{array}{l}.153 \\
(.111)\end{array}$ & $\begin{array}{l}.399^{* * *} \\
(.104)\end{array}$ & $\begin{array}{c}.252^{*} \\
(.104)\end{array}$ \\
\hline simultaneous transitions & & & & $\begin{array}{l}.080 \\
(.187)\end{array}$ & $\begin{array}{l}-.709^{* * *} \\
(.158)\end{array}$ & $\begin{array}{l}-.126 \\
(.156)\end{array}$ \\
\hline constant & $\begin{array}{c}.077 \\
(.172) \\
\end{array}$ & $\begin{array}{r}.179 \\
(.125) \\
\end{array}$ & $\begin{array}{c}.097 \\
(.102)\end{array}$ & $\begin{array}{c}.080 \\
(.172) \\
\end{array}$ & $\begin{array}{c}.164 \\
(.124)\end{array}$ & $\begin{array}{c}.096 \\
(.102)\end{array}$ \\
\hline$N$ observations & 1836 & 3067 & 3675 & 1836 & 3067 & 3675 \\
\hline$N$ individuals & 1167 & 1707 & 1836 & 1167 & 1707 & 1836 \\
\hline
\end{tabular}

* $p<0.05 ;{ }^{* *} p<0.01 ;{ }^{* * *} p<0.001$, two-tailed;

Bold coefficients differ across educational groups at the $p<0.05$ level (Wald tests of equality of coefficients in pooled analyses with interactions by educational level).

Note that the total individual sample is larger than that of table $3(4,710$ versus 4,192$)$ because we used a time-varying indicator of educational level and so individuals can belong to several educational categories. 
We did find a significant interaction of education and the impact of experiencing simultaneous transitions (table 4, model 2). Contrary to our expectation, however, the experience of simultaneous adverse transitions appears to be especially harmful for the intermediate educational group. The highest educational group is also negatively affected but less strongly, whereas there is no effect for the lowest educated. This may reflect on the one hand that resources protect the highest educated from suffering more when experiencing simultaneous transitions but, on the other hand, possible floor effects that do the same for the lowest educated groups. Once we allow for simultaneous effects, some of the two-way interactions become significant. Especially, the highest educated appear to suffer more from unemployment. This suggests that the income and status 'fall' after unemployment can be greater for those with high-status jobs.

\section{Conclusion and discussion}

In this study, we examined the question of whether experiencing several adverse life course transitions in a relatively short period of time has interactive (accumulating) detrimental effects for mental health or whether the effects are merely additive. Empirically, we tackled this question using a large four-wave panel study in the Netherlands with about three to four years between subsequent waves. We examined transitions with potential negative consequences for mental health in three important life course domains: partner loss and the death of a parent in the family domain; becoming unemployed in the work domain; and the onset of disability in the health domain.

We found that each of the delineated adverse transitions had its predicted negative consequence for mental health, except for the death of a parent. The onset of disability had the largest effect, followed by the loss of a partner and unemployment. The experience of combined adverse transitions in the span of time between two subsequent waves of the study led to an extra negative effect on mental health, on top of the main effects of the component transitions. More specifically, the accumulative effect of two simultaneous effects was worse than would be expected given the sum of these effects. In other words, there seems to be interactive and not simply additive accumulation of misery during the life course.
Theoretically, we interpret this finding in terms of resources and vulnerability. We believe that simultaneous adverse transitions can have interactive effects because people are psychologically more vulnerable to the effects of a second adverse transition after just going through one. In addition, the first adverse event may decrease people's social and economic resources, which may make them more vulnerable to future adverse transitions. We also developed alternative hypotheses about floor effects and support mobilisation, but these apparently do not play a role or at least are not strong enough to overturn the interaction effect. Our finding that the accumulation effect is weaker for the higher educated - who will be more likely to mobilise professional help - could point in this direction, however.

Conceptually, we moved beyond the "one transition at a time" and the "life events" literatures by examining four transitions in different domains of life. Even in the relatively long span of time between subsequent waves, three to four years, the effects of simultaneous transitions on mental health accumulate. It seems that, especially when unemployment was added to the mix, the effects worsened. Although we do not have information on the order of events, we suppose that the effects accumulate because the first adverse transition that occurs erodes people's ability to cope with subsequent adverse events. Unemployment erodes financial resources and may put a strain on social resources so that a subsequent event, such as the death of a parent, comes as a much bigger blow. It is also possible that a first adverse transition sets in motion an adverse chain of events, for instance unemployment leading to divorce. Unfortunately, we were not able to investigate such processes given the relatively long time interval between waves in this study.

It is also possible that people experience simultaneous adversity (e.g. unemployment and partner loss) as a result of a mental health breakdown or because of other external events that affect both mental health and the chance of negative transitions. Observational studies are not able to rule out such alternative narratives but the clear existence of accumulation in the life course (be it cause and/or effect) points to the need for future studies of single life course transitions, such as job loss, to carefully consider the role of 
transitions in other domains of life, as they may have exacerbating effects and/or may be part of adverse chain of transitions. Longitudinal studies using shorter time intervals (preferably yearly) than we had available would be especially suited for this task.

\section{References}

Amato, P. R. (2000). The consequences of divorce for adults and children. J Marriage Fam, 62, 1269-1287. https://doi.org/10.1111/j.1741-3737.2000.01269.x

Amato, P. R. \& Cheadle, J. (2005). The long reach of divorce: Divorce and child well-being across three generations. J Marriage Fam, 67, 191-206. https://doi.org/10.1111/j.0022-2445.2005.00014.x

Amato, P. R. \& Rogers, S. J. (1997). A Longitudinal Study of Marital Problems and Subsequent Divorce. J Marriage Fam, 59, 612. https://doi.org/10.2307/353949

Ballas, D. \& Dorling, D. (2007). Measuring the impact of major life events upon happiness Int J Epidemiology, 36, 1244-1252. https://doi.org/10.1093/ije/dym182

Bernardi, F. \& Radl, J. (2014). The long-term consequences of parental divorce for children's educational attainment. Demographic Research, 30, 1653-1680. https://doi.org/10.4054/DemRes.2014.30.61

Berwick, D. M., Murphy, J. M., Goldman, P. A., Ware, J. E., Barsky, A. J. \& Weinstein, M. C. (1991). Performance of a Five-Item Mental Health Screening Test. Medical Care, 29, 169-176. https://doi.org/10.1097/00005650-199102000-00008

Charles, K. K. \& Stephens, M. (2004). Job displacement, disability, and divorce. J Labor Econ, 22, 489-523. https://doi.org/10.1086/381258

Clark, A. E., Georgellis, Y. \& Sanfey, P. (2001). Scarring: The Psychological Impact of Past Unemployment. Economica, 68, 221-241. Clark, A. E., Georgellis, Y. \& Sanfey, P. (2001). Scarring: The Psychological Impact

Covizzi, I. (2008). Does Union Dissolution Lead to Unemployment? A Longitudinal Study of Health and Risk of Unemployment for Women and Men Undergoing Separation. Eur Sociol Rev, 24, 347-361. https://doi.org/10.1093/esr/jen006

Cuijpers, P., Smits, N. Donker, T., ten Have, M. \& de Graaf, R. (2009). Screening for mood and anxiety disorders with the five-item, the three-item, and the two-item Mental Health Inventory. Psychiatry Research, 168, 250. https://doi.org/10.1016/j.psychres.2008.05.012

De Graaf. P. \& Ganzeboom, H. B. G. (1993). Family background and educational attainment in the Netherlands for the 1891-1960 birth cohorts. In Y. Shavit \& H-P. Blossfeld (Eds.), Persistent inequality: Changing educational attainment in thirteen countries (pp 75-99). Boulder, Co.: Westview Press.

Dooley, D., Fielding, J. \& Levi, L. (1996). Health and Unemployment. Annu Rev Publ Health, 17, 449-465. https://doi.org/10.1146/annurev.pu.17.050196.002313

Dykstra, P.A., Kalmijn, M., Knijn, T. C. M., Komter, A. E., Liefbroer, A. C. \& Mulder, C. H. (2005). Codebook of the NKPS, a multi-actor, multi-method panel study on solidarity in family relationships, Wave 1 . The Hague: NIDI.

García Gómez, P. \& López Nicolás, A. (2006). Health shocks, employment and income in the Spanish labour market. Health Economics, 15, 997-1009. https://doi.org/10.1002/hec.1151

Giver, H., Faber, A., Hannerz, H., Strøyer, J. \& Rugulies, R. (2010). Psychological well-being as a predictor of dropout among recently qualified Danish eldercare workers. Scand J Public Healt, 38, 239-245. https://doi.org/10.1177/1403494809348939

Hansen, H-T. (2005). Unemployment and Marital Dissolution: A Panel Data Study of Norway. Eur Sociol Rev, 21, 135-148. https://doi.org/10.1093/esr/jci009

de Hoon, S., Dykstra, P. A., Komter, A. E., Liefbroer, A. C. \& Mulder, C. H. (2015). Codebook of the NKPS, a multi-actor, multi-method panel study on solidarity in family relationships, Wave 4. The Hague: NIDI.

Kalmijn, M. (2005). The Effects of Divorce on Men's Employment and Social Security Histories. Eur J Popul, 21, 347. https://doi.org/10.1007/s10680-005-0200-7 
Kasl, S. V. \& Jones, B. A. (2000). The impact of job loss and retirement on health. In L. F. Berkman \& I. Kawachi (Eds.), Social Epidemiology, pp118-136. New York, NY: OUP.

Kelley-Moore, J. A. \& Ferraro, K. F. (2005). A 3-D Model of Health Decline: Disease, Disability and Depression among Black and White Older Adults. J Health Soc Behav, 46, 376-391. https://doi.org/10.1177/002214650504600405

Kessler, R. C. (1997). The effects of stressful life events on depression. Annu Rev Psychol, 48, 191-214. https://doi.org/10.1146/annurev.psych.48.1.191

Koning, P. W. C. \& van Vuuren, D. J. (2010). Disability insurance and unemployment insurance as substitute pathways. Applied Economics, 42, 575-588. https://doi.org/10.1080/00036840701704436

Korpi, T. (2001). Accumulating disadvantage: Longitudinal analyses of unemployment and physical health in representative samples of the Swedish population. Eur Sociol Rev, 17, 255-273. https://doi.org/10.1093/esr/17.3.255

Lantz, P. M., House, J. S., Mero, R. P. \& Williams, D. R. (2005). Stress, Life Events, and Socioeconomic Disparities in Health: Results from the Americans' Changing Lives Study. J Health Soc Behav, 46, 274288. https://doi.org/10.1177/002214650504600305

Lucas, R. E. (2007). Long-Term Disability is Associated with Lasting Changes in Subjective Well-Being : Evidence from Two Nationally Representative Longitudinal Studies. J Pers Soc Psychol, 92, 717-730. https://doi.org/10.1037/0022-3514.92.4.717

Mandemakers, J. J. \& Kalmijn, M. (2014). Do mother's and father's education condition the impact of parental divorce on child well-being? Soc Sci Res, 44, 187-199. https://doi.org/10.1016/j.ssresearch.2013.12.003

Mandemakers, J. J. \& Monden, C. W. S. (2010). Does education buffer the impact of disability on psychological distress? Soc Sci Med, 71, 288-297. https://doi.org/10.1016/j.socscimed.2010.04.004

Mandemakers, J. J. \& Monden, C. W. S. (2013). Does the effect of job loss on psychological distress differ by educational level? Work, Employ Soc, 27, 73-93. https://doi.org/10.1177/0950017012460312

Mandemakers, J. J., Monden, C.W.S. \& Kalmijn, M. (2010). Are the Effects of Divorce on Psychological Distress Modified by Family Background? Adv Life Course Res, 15:27-40. https://doi.org/10.1016/j.alcr.2010.08.002

Marks, N. F., Jun, J. \& Song, J. (2007). Death of Parents and Adult Psychological and Physical Well-Being: A Prospective U.S. National Study. J Fam Issues, 28, 1611-1638. https://doi.org/10.1177/0192513X07302728

McLeod, J. D. \& Kessler, R. C. (1990). Socioeconomic status differences in vulnerability to undesirable life events. J Health Soc Behav, 31, 162-172. https://doi.org/10.2307/2137170

Oswald, A. J. \& Powdthavee, N. (2008). Does Happiness Adapt? A Longitudinal Study of Disability with Implications for Economists and Judges. J Public Econ, 92, 1061-1077. https://doi.org/10.1016/j.jpubeco.2008.01.002

Paul, K. I. \& Moser, K. (2009). Unemployment impairs mental health: Meta-analyses. J Voc Behav, 74, 264. https://doi.org/10.1016/i.jvb.2009.01.001

Reynolds, J. R. \& Turner, R. J. (2008). Major Life Events: Their Personal Meaning, Resolution, and Mental Health Significance. J Health Soc Behav, 49, 223-237. https://doi.org/10.1177/002214650804900208

Schuring, M., Burdoff, L., Kunst, A. \& Mackenbach, J. (2007). The effects of ill health on entering and maintaining paid employment: evidence in European countries. J Epidem Comm Health, 61, 577604. https://doi.org/10.1136/iech.2006.047456

Strully, K. W. (2009). Job Loss and Health in the U.S. Labor Market. Demography, 46, 221-246. https://doi.org/10.1353/dem.0.0050

Thoits, P. A. (1982). Life Stress, Social Support, and Psychological Vulnerability: Epidemiological Considerations. J Community Psych, 10, 341-62. https://doi.org/10.1002/15206629(198210)10:4<341::AID-JCOP2290100406>3.0.CO;2-J

Turner, R. J. \& Avison, W. R. (1992). Innovations in the Measurement of Life Stress - Crisis Theory and the Significance of Event Resolution. J Health Soc Behav, 33, 36-50. https://doi.org/10.2307/2136856 
Turner, R. J. \& Noh, S. (1988). Physical Disability and Depression: A Longitudinal Analysis. J Health Soc Behav, 29, 23-37. https://doi.org/10.2307/2137178

Turner, R. J., Wheaton, B. \& Lloyd, D. A. (1995). The Epidemiology of Social Stress. Am Soc Rev, 60, 104-125. https://doi.org/10.2307/2096348

Umberson, D. (1995). Marriage as Support or Strain? Marital Quality Following the Death of a Parent. J Marriage Fam, 57, 709. https://doi.org/10.2307/353925

Van de Mheen, H., Stronks, K., Schrijvers, C. T. \& Mackenbach, J. P. (1999). The influence of adult ill health on occupational class mobility and mobility out of and into employment in the Netherlands. Soc Sci Med, 49, 509. https://doi.org/10.1016/S0277-9536(99)00140-9

Wagenaar, A. F., Kompier, M. A. J., Houtman, I. L. D., van den Bossche, S. N. J. \& Taris, T.W. (2012). Employment Contracts and Health Selection Unhealthy Employees Out and Healthy Employees In? J Occup Environ Med, 54, 1192-1200. https://doi.org/10.1097/JOM.0b013e3182717633

Wheaton, B. (1990). Life transitions, role histories and mental health. Am Soc Rev, 55, 209-223. https://doi.org/10.2307/2095627

Wilson, S. E. \& Waddoups, S. L. (2002). Good Marriages Gone Bad: Health Mismatches as a Cause of LaterLife Marital Dissolution. Pop Res Policy Rev, 21, 505-533. https://doi.org/10.1023/A:1022990517611 